\title{
UNA MIRADA A LA OBRA DE CARLA CORDUA
}

\author{
Marcos García de la Huerta
}

Es un honor poder expresar en nombre de ustedes y del Departamento de Filosofía, la satisfacción y alegría con que recibimos el otorgamiento del Premio Nacional de Humanidades a Carla Cordua y Roberto Torretti. Agradezco, pues, a Carlos Ruiz el haberme confiado esta grata tarea. Hay varios motivos para celebrar: el más importante quizá es que esta decisión le da jerarquía al Premio: han salido ganando las humanidades. Es gratificante también, para quienes nos dedicamos a la filosofía, que el galardón recayera en dos colegas de profesión. En fin, tengo un motivo adicional para compartir esta alegría, porque me une a ellos una amistad fortalecida a lo largo de años; los conocí en el Centro de Estudios Humanísticos donde colaboré y compartí con ellos el ensayo de "descuadrar" a los ingenieros; también el de leer durante tres largos años la Fenomenología del espíritu, como señaló Eduardo (Carrasco) recién. Por eso al conocer el veredicto que concedió el Premio por partida doble, me pareció que se hacía doblemente justicia y se conseguía lo imposible: fallar y acertar.

El mejor homenaje que se puede hacer a un autor es leerlo, claro, pero no estamos aquí para eso. Podemos sí, sugerir algunas ideas a modo de introducción a su lectura y preguntar cómo abordar esta obra múltiple y compleja, diáfana, sin embargo, gracias a una escritura desenvuelta y natural. Se inicia con tres excelentes libros sobre Hegel: la filosofía del derecho y del arte; continúa con el análisis y discusión del pensamiento de los principales filósofos del siglo XX, todo eso cruzado con ensayos lúcidos y profundos sobre poetas y narradores, de preferencia también contemporáneos. La relación entre estos dos aspectos -el filosófico y el literario-, constituye todo un envite, que bien podría llevarnos tiempo completo. Me limitaré pues, a proponer algunas líneas de exploración de este vastísimo universo, siguiendo algunas pistas que la misma autora ha sugerido.

Los filósofos interpelados, aparte de Hegel, son: Sartre, Wittgenstein, Heidegger y Sloterdijk, en ese mismo orden; los escritores hacen legión: Kafka, Dostoievski, Naipaul, Coetzee, José Luis Martínez, entre muchos otros. "El estudio de la obra de Hegel, al que dediqué unos seis años, señala Carla, responde a 'un empeño de autoeducación', "nunca pretendí plegarme a la manera de pensar de Hegel”. ¿Y los contemporáneos -se pregunta uno- no contribuyen también a la "auto educación"? Ella no menciona este motivo en esos casos, lo reserva para Hegel, que es precisamente con quien difiere. ¿Ha de haber entonces, tratándose de aquellos, una motivación adicional o un interés distinto al de la autoeducación?

Una respuesta provisoria sería: establecer con ellos un diálogo sobre cuestiones que ella misma quiere despejar. "Para decidir acerca de qué pensar me reservaba a los filósofos del siglo XX. Luego me pasé a los 4 [nombrados] del siglo pasado y ahí, en relación con ellos, se formó mi manera de pensar". Lo que uno mismo piensa es la instancia decisiva, aunque no definitiva ni concluyente; el sujeto que piensa es un yo, un yo situado, no aislado. El pensamiento es algo que tiene lugar: se da en un sitio, a 
partir de una experiencia del mundo y acontece en una suerte de diálogo interminable consigo mismo y con otros: a través de ellos y de mi experiencia del mundo encuentro las palabras, el estilo y las formas que expresan "mi manera de pensar". No se trata, pues, de historia de las ideas, sino de que pienso entre otros "yo", desde y a través de ellos, con ellos, quizás a veces contra ellos, toda la gama de las preposiciones cabe aquí, salvo alguna que indique subordinación; la autoridad no es criterio. Leer es un acto que dilata mi mundo y libera mi subjetividad, no la anula ni la neutraliza.

Sartre, Heidegger, Wittgenstein y Sloterdijk. ¿Tienen algo en común? Se podría decir que todos son "post metafísicos", corriendo el riesgo de simplificar, sobre todo en el caso de Sartre. Afirmar que Heidegger y Sartre son fenomenólogos, sería una verdad a medias; que ambos son "filósofos de la existencia", no lo descarta el propio Heidegger, pero "filosofía de la existencia es como decir "botánica de las plantas", ironiza él mismo. La lectura de Sartre, en todo caso, es más episódica e incidental. Quizá el interlocutor más continuo y gravitante sea Heidegger, aunque no por eso el más próximo; el acercamiento con Sloterdijk se produce, en parte, creo, en el post heideggerismo. La convergencia de Wittgenstein con Heidegger en la recusación de la teoría es particularmente significativa, pero es un punto que quisiera retomar luego de un breve paréntesis, que abro aquí -ya que se trata de un Premio Nacional y de Humanidades-, para referirme al sitio y a la situación de las humanidades.

En un artículo reciente sobre La crisis de las humanidades, precisamente, Carla aborda este problema a propósito de un libro de Martha Nussbaum: Sin fines de lucro. Por qué la democracia necesita de las humanidades. Esta crisis es un fenómeno global, que golpea con mayor intensidad a las sociedades con menor espesor cultural, pero cuando se globaliza la deuda, el desempleo y el déficit público, nadie está a salvo. La obsesión por conseguir el desarrollo económico, observa Carla, lleva a los "planificadores de la educación a programar la formación de los educandos teniendo en vista principalmente [...] el adiestramiento técnico y la enseñanza puramente utilitaria", en detrimento de las humanidades cuyo sentido es la formación en el pensamiento libre y la preparación para "el desempeño de una ciudadanía consciente y responsable". La crisis de las humanidades pasa un tanto desapercibida, agrega, frente a la mayor visibilidad mediática de la crisis financiera, pero, aunque más silenciosa e inaparente, es más grave y profunda. Es sintomático que la misma debacle de las finanzas provoque solo discusiones sobre regulación de los mercados y ningún debate sobre la inseguridad, la desconfianza y la destrucción del mundo común. En contraste con el reiterado anuncio del desarrollo a la vuelta del decenio, la autora presagia que "la pérdida de la cultura humanística, traerá consigo la ruina de las sociedades democráticas".

La crisis de las humanidades ha ido de la mano en nuestro país con la extensión de la lógica del mercado y la precarización de la educación pública. El mantra del desarrollo ha llevado a que "los estudios humanísticos [sean] gravemente recortados y arrinconados", señala Carla. "La disminución del tiempo que se solía dedicar en la educación secundaria a la filosofía" y la eliminación de la educación cívica en la secundaria, son ejemplos significativos; a los que se agregan las pruebas estandarizadas con alternativas, que suplantan la lectura y la comprensión, y desde luego, toda la serie de arremetidas contra la educación pública, cuyo blanco principal ha sido la 
Universidad de Chile. Primeramente, le amputaron todas las sedes de provincias y, a cambio, le dejaron todas las deudas; para remate, le impusieron la regla del auto financiamiento: "dispositivos de la gubernamentalidad neoliberal", diría Foucault. Shock era el tecnicismo consagrado para justificar este tipo de medidas que, en rigor, eran parte de un golpe de mercado paralelo y complementario del golpe militar.

Cabe, entonces, preguntar si la crisis de las humanidades y la ruina de la democracia no son caras de la misma moneda, o los dos rostros de Jano: el dios de los inicios y de los finales. El mercado libre, que originalmente estaba para organizar la economía y limitar la razón de Estado, termina organizando la sociedad y subordinando al Estado, produciendo una mercadocracia, que anula y suplanta al ciudadano. No importa que nadie crea ya en el mito de la mano invisible: se adoptó la moraleja sin conocer la fábula. La mercantilización desarrolla la economía, pero destruye el mundo común: queda la feria, el mercado original, o mercado y policía: el sueño liberal clásico. La amenaza a la democracia siempre se representó en términos de desmesura de la razón política. Las utopías negativas, invariablemente vieron el sujeto de la pesadilla que describen, en la acción del Estado. El "Gran Hermano" de Orwell, el Mundo feliz de Huxley o los bomberos pirómanos de Bradbury presentan un poder estatal ilimitado o un ordenamiento pretendidamente "científico" del colectivo, impuesto desde arriba; nunca se representó el potencial distópico que contiene la razón económica ilimitada. Quizá porque el poder económico se impone seduciendo, desde abajo, haciendo creer a todo el mundo que el interés y el afán posesivo son una base suficiente de un cuerpo político.

Se ha convertido en un lugar común afirmar que una educación pública gratuita es "injusta", que es un subsidio a los más pudientes. Se subsidia a los bancos, a las AFP, a las concesionarias, indirectamente a las Isapres y desde luego a las instituciones de la defensa. ¿Por qué duele tanto un subsidio a la educación? Los teóricos de la privatización procuran una respuesta menos hipócrita. Hayek, por ejemplo, escribe: "no cabe mayor peligro para la estabilidad política de un país, que la existencia de un auténtico proletariado intelectual sin oportunidades para emplear el acervo de sus conocimientos" (Hayek, Friedrich, Los fundamentos de la libertad, tomo segundo, Folio, 1996, p. 457). Lo cierto es, que de haberse conjurado a tiempo esa supuesta injusticia, jamás habrían existido universidades nacionales como la Universidad de Chile. Si Andrés Bello se hubiera preguntado: ¿Se financiará?, jamás la habría creado. La pura lógica económica no sirve de nada cuando los beneficios son incalculables. Digámoslo con franqueza: con la sola racionalidad económica nunca se habría creado este país, que se sostiene básicamente liquidando sus riquezas naturales, que es como procurarse el sustento vendiendo la sangre.

No me aparto con esto de Carla; tan solo abundo en el papel protagónico de la educación pública en un sistema mixto, por su doble función creativo-inventiva y reguladora. "Una cultura capaz de renovarse creadoramente, escribe, necesita fuerzas que no procedan exclusivamente de una educación para el lucro o de una inspirada solo en el crecimiento económico". 
Frecuentemente, se asocia el derecho a la educación con la educación pública garantizada por el Estado, en tanto a la educación privada se la identifica, algo abusivamente, con negocio. Un establecimiento no es público, sin embargo, por pertenecer al Estado: una universidad puede ser estatal, reconocer como "patrono" al Jefe de Estado y obedecer a una lógica estrictamente "privada". La ley que prohíbe el lucro ¿no buscaba mantener la especificidad de la academia independientemente de la propiedad? La eficiencia y la producción de excedentes no están reñidos con la academia, pero si la eficiencia se entiende en términos de ganancia, desaparece la distinción entre lo público y lo privado. Prohibir el lucro y convertir la universidad en empresa, no son objetivos compatibles: es el zorro a cargo del gallinero. En cambio, no ser negocio y ser gratuita, sí son compatibles. De hecho, la Universidad pública cumplía ambos requisitos. Pero la cosa era así: la Universidad de Chile, por disposición constitucional, recibía el 2\% del Presupuesto nacional; eso equivaldría en el presupuesto actual, a unos 600.000 millones de pesos (o 1.200 millones de dólares); solo recibió menos del 7\% de eso, unos 40.000 millones de aporte directo. Había además, un Fondo de Investigación Universitaria que percibía el $1 / 2 \%$ de todos los impuestos directos e indirectos más el $1 \frac{1}{2} \%$ de los Derechos de Aduana y exportación (la ley 11.575 de 1954 concedía este beneficio por 20 años). El Presupuesto de Educación alcanzaba el 7\% del Producto; 40 años después, el Presupuesto llega al 4\% del PIB (Producto Interno Bruto).

"La Universidad de Chile nunca debió haber nacido" es el corolario de la lógica mercantil ¿Por qué debería haber monopolios públicos? Es una pregunta reñida con las evidencias, pues lo cierto es que la universidad pública siempre coexistió con las privadas. La mercantilización, en cambio, destruye un sistema mixto, porque al concebir la educación como "bien escaso" o de consumo, se la niega como derecho y se la inscribe en la lógica del mercado. El punto es, entonces, que una institucionalidad que se debilita o desaparece plantea la cuestión sobre la posibilidad de supervivencia de aquello que ella permitió que surgiera.

"No hay nada gratis en la vida", se ha dicho, entendiendo impugnar así el lema: "sin fines de lucro". Pero la afirmación misma es gratuita: que "nada sea gratis" significa que todo es mercancía, que nada hay intransable, que todos somos vendedores o vendidos. Se puede hacer el ensayo de monetarizar todo, pero eso sí que no es gratis: es una "catástrofe moral en potencia", afirma Tony Judt (Pensar el siglo $X X)$, pero es más bien una catástrofe en acto o en pleno desarrollo: la anunciada ruina de la democracia ya está aquí. La fórmula de Nussbaum se puede invertir: con fines de lucro significa sin fines de democracia. Sin embargo, la sociedad democrática requiere del lucro; los estímulos morales y políticos por sí solos, son insuficientes; la mayor parte de la gente no actúa por motivos altruistas. Por lo demás, solo como ciudadanos somos iguales, en el mercado, somos diferentes: nos distingue el poder de compra como clientes y el poder de venta como productores. Por eso, para restringir la educación a los que pueden pagarla, basta concebirla como "bien de consumo" o "bien escaso". La virtud cívica, el altruismo y la decencia también son "escasos", pero no por ponerles precio se vuelven abundantes; se convierten más bien en otra cosa o en su contrario. El mercado reduce al ciudadano a cliente 
y productor. Solo por el lado de la ficción democrática, afirmando lo que tenemos los humanos en común, es posible sobrepasar esta contraposición. Carla lo expresa así: "Somos inducidos a convertirnos en productores de bienes monetarios [...] Pero nada garantiza que las personas entrenadas solo en generar ingresos sean capaces de construir sociedades en las que valga la pena vivir".

Volviendo ahora al punto donde ella planteaba una convergencia entre Heidegger y Wittgenstein, decíamos que esa proximidad la establece en la recusación de la teoría. En el caso de Heidegger, a través de su propuesta de "otro pensar", uno que supere la modalidad representativo-objetivante, cuya máxima expresión es la razón científico-técnica moderna. Wittgenstein, por su parte, entiende el ejercicio de la razón ante todo como un trabajo sobre la lógica del lenguaje común, que pasa por la crítica del lenguaje de la lógica, de la metafísica y de la ciencia. Esta crítica de la teoría ha pasado un tanto desapercibida en el pensamiento de Wittgenstein, afirma Carla, frente a la preeminencia concedida al rigor analítico de sus Investigaciones, pero, es precisamente su radical exigencia de racionalidad lo que lleva a Wittgenstein a su crítica de la razón lógica, por la vía del análisis del lenguaje. Él denuncia la ambición de la filosofía de comprender el todo y en especial su aspiración a cambiar el mundo: la filosofía "deja todo tal cual", dice. Pero lo cierto es, acota Carla, que Wittgenstein está muy lejos de guardar una actitud neutral frente al estado presente del mundo. "No es insensato creer, escribe Wittgenstein, que la época científica y técnica es el comienzo del fin de la humanidad; [...] que no hay nada bueno o deseable en el conocimiento científico y que la humanidad que lo busca se precipita en una trampa" (Vermischte Bemerkungen, Suhrkamp, Frankfurt am Main, p. 529). Y, a propósito de la bomba, agrega: "El miedo histérico que el público le tiene ahora a la bomba atómica, o, al menos, el que expresa, es casi un signo de que con ella se ha hecho, por una vez, un invento saludable. Este miedo da la impresión de que [en el caso de la bomba] se trata de una medicina amarga verdaderamente efectiva. No me puedo deshacer de la idea: si aquí no hubiese algo bueno no gritarían los filisteos. Pero tal vez este no sea más que un pensamiento pueril. Pues lo que puedo opinar no es otra cosa sino que la bomba deja entrever el fin, la destrucción, de un horrible mal, la repugnante y babosa ciencia. Y esta no es una idea desagradable, por cierto" (Vermischte Bemerkungen, Suhrkamp, Frankfurt am Main 1984, p. 96).

Carla plantea pues, a través de Wittgenstein y de Heidegger, su crítica a una concepción mesiánica de la ciencia, difundida por el romanticismo, que ha construido una imagen bucólica: la figura del científico solitario, desinteresado, que brinda mediante sus conocimientos enormes beneficios a la humanidad a cambio de nada, por lo que la humanidad le debe tributo y veneración. Pero la idea de que la ciencia es pura y en sí misma neutra y desinteresada, lo mismo que su pretendida primacía sobre la técnica, es una ficción. El texto recién citado, lo que impugna es la ciencia misma: la física o cualquiera que siga su padrón, es decir, todas; es el tipo de racionalidad lo que está en entredicho, porque, lejos de ser neutral, representa una amenaza: la bomba es solo un símbolo; hoy sabemos que la química es tanto si no más peligrosa para la vida que la misma bomba. 
La reserva frente a la teoría, que Carla comparte con Heidegger y con Wittgenstein, expresa una distancia o despego frente a las manifestaciones postreras de la metafísica moderna. Entiendo que cuando ella enfatiza que la traducción de Gelassenheit por serenidad es incorrecta, y que significa más bien desasimiento y desapego, apunta a esto justamente. La superación de la metafísica de la voluntad de poder se expresa por lo menos en un desapego, en una Abneigung, más próxima de la aversión de Wittgenstein frente a las pretensiones del logos científico-técnico que de la serenidad sosegada.

Pero quisiera sugerir todavía otra arista de la crítica de la teoría y del discurso logo-céntrico: su relación problemática con el discurso falo-céntrico de cuño platónico. Lo que se ha llamado también "falogocentrismo".

La cuestión de la teoría en Grecia surgió asociada a la vida en la polis: se planteaba la relación entre el bios teoretikos y el bios politikos, a propósito de la competencia del filósofo y de los hombres de oficio en las decisiones sobre los asuntos públicos. Tanto Platón como Aristóteles concibieron la teoría asociada a los conceptos universales, en particular a las entidades geométricas, respecto de las cuales se trataba de establecer su vínculo con lo sensible, con los objetos de la intuición sensorial. Platón estableció una correlación entre la jerarquía de los saberes y las jerarquías en la polis: la diferencia en cuanto al saber distingue y separa categorías de humanos. La techné politiké o arte de gobernar exige como cualquier techné, una competencia específica que, en el caso de la política, sería de orden teórico. El herrero, el curtidor o el sastre posee, cada uno en su oficio, una habilidad, un saber-hacer pre-teórico, que se legitima por su misma funcionalidad y utilidad, y no requiere de justificación. Pero la teoría no se justifica por sí misma: será preciso una teoría de la teoría, que valide la actividad del filósofo frente a las demás prácticas y a los ojos de la ciudad. Platón sostiene, precisamente, que el arte de gobernar requiere de un saber que solo detentan los sabios, los hombres de la teoría, no así los artesanos, que solo poseen destrezas, que no habilitan para la participación en los asuntos de la ciudad. Junto con establecer el primado original del bios theoretikos sobre el bios politikos, Platón sienta la base conceptual de la moderna legitimación logo-técnica del poder. La teoría nace como un modo de pensamiento restrictivo, reservado a una categoría especial de humanos -los filósofos-, que se distinguen de todos los demás porque poseen un saber al que no puede acceder el común de los humanos, en particular los artesanos. A diferencia del saber operativo, la teoría es pura y su práctica, forma en la virtud.

Protágoras, en el diálogo del mismo nombre, es la voz que contrasta esta concepción platónica de la teoría; él defiende la participación de los artesanos en política: solo la de ellos; no había en Grecia la voz equivalente a la suya para abogar por la participación de otras minorías. La capacidad de las mujeres, por ejemplo, para decidir en los asuntos políticos no era siquiera cuestión. Pero el argumento de Protágoras no vale solo para los artesanos, es extensible al común de los mortales. La teoría o episteme teoretikos determina una categoría genérica de no sapientes que están de más, que no tienen derecho a actuar ni siquiera como hablantes u opinantes. Son los hombres, los hombres de la teoría, quienes poseen en exclusiva el arte de gobernar o techné politiké, la capacidad de decidir en los asuntos públicos. Pero Protágoras niega la pertinencia 
del primado de la teoría en la política y con eso desbarata las exclusiones implicadas en el distingo platónico; él diferencia el ser competente en algo y el estar concernido por ello. Una cosa es saber navegar o ser perito en asuntos de navegación, por ejemplo, para lo cual, efectivamente, hay que ser marino, pero en las decisiones que conciernen a la ciudad hay algo común, un común dividido, litigioso, pero del que nadie debe ser excluido, precisamente porque son asuntos que atañen a todos. Para que pueda haber ciudades, todos deben participar en la virtud pública.

Cabe preguntar -con esto termino-, si la inclinación de Carla hacia la literatura guarda una relación con su interrogación filosófica, o se trata solo de una afición, una actividad que se realiza por el puro gusto. La poética y la narrativa incursionan en aspectos de la experiencia que la teoría se proscribe o le son negados. Las valoraciones y normas -inherentes al actuar en el mundo-, no deben permear la pureza de la teoría, que se quiere "libre de valores". Ella procede sometiendo las diferencias al universal genérico del concepto, al revés de la narración, que se nutre y enriquece con los pormenores y particularidades. Los testimonios, por ejemplo, pueden ser reveladores con solo ser "veraces", sin pretender verdad; un relato de ficción en este aspecto tendría un estatus hasta cierto punto equivalente a uno de no ficción. Y una biografía, como bien mostró Dilthey, es un reflejo del mundo. Más aun: los relatos biográficos o historiográficos son constituyentes: las identidades se construyen narrativamente. Una trama temporal posee una profundidad propia, no lógica, y a la vez que confiere unidad a lo vivido, lo procesa produciendo sujetos. La pregunta que queda abierta, se refiere a la relación del "otro pensar" (Heidegger) con la poesía, la narrativa y el mundo común, entendido como mundo de la vida y como mundo compartido. ¿Es casual, que los filósofos interpelados sean invariablemente fenomenólogos o filo-fenomenólogos? La descripción como método es un punto de convergencia con la narrativa y con una puesta entre paréntesis de la teoría. En este aspecto, me atrevo a afirmar que el giro que se produce en la filosofía del siglo XX a partir del Husserl de La Crisis, deja una impronta en la producción de Carla, y la aparta al mismo tiempo, decididamente, de Heidegger. Pero esto sería materia de otro estudio. Muchas gracias. 